\title{
Leprosy on the Rise in India: Need to Adopt Enhanced Strategy for its Control
}

\section{Mane Abhay B*}

Professor, Department of Community Medicine, Smt. Kashibai Navale Medical College, Pune, Maharashtra, India

Leprosy is believed to be one of the oldest recorded diseases, with references dating back to Biblical times and medical evidence from skeletons indicating it originated in India in around 2000 BC. Leprosy is a chronic disease caused by a bacillus, Mycobacterium leprae, an acid-fast, rod-shaped bacillus. M. leprae multiplies very slowly and the incubation period of the disease is about five years. Symptoms can take as long as 20 years to appear. Leprosy is not highly infectious. It is transmitted via droplets, from the nose and mouth, during close and frequent contacts with untreated cases. Untreated, leprosy can cause progressive and permanent damage to the skin, nerves, limbs and eyes. Early diagnosis and treatment with Multidrug Therapy (MDT) remains the key in eliminating the disease as a public health concern, as per the World Health Organization.

\section{Current Leprosy Scenario in India}

India officially eliminated leprosy nine years ago, but reports now suggest that the cases of leprosy are going up, especially in urban areas. India accounts for 58 percent of newly diagnosed leprosy cases in the world, according to the World Health Organization [1]. As shown in Figure 1, a total of 1.35 lakh new cases were detected during the year 2012-13, which gives Annual New Case Detection Rate (ANCDR) of 10.78 per 100,000 population. This shows increase in ANCDR of $4.15 \%$ from $2011-12$ (10.35). The prevalence rate (PR) was 0.73 per 10,000 population with child case rate of 1.07 per $1,00,000$ population [2]. It was reported that 33 States/Union Territory (UT) have achieved elimination of leprosy with a PR less than 1 per 10,000 populations except 1 state and 1 UT. The 3 states that had achieved elimination showed an alarming rise in the PR level above 1. Also Proportion of Child cases was more than $10 \%$ of new cases detected in 12 States/UTs.

As on $31^{\text {st }}$ March 2013, 87 districts had ANCDR above 20/10,000 population while the number of districts with $\mathrm{PR}>1$ has gone up from 98 to 121 (Figures $2-4$ ). Grade II disability rate $>2$ /million population has been reported in 304 districts (46.84\%). A record $92.5 \%$ of newly detected cases were released as cured with multidrug therapy during

\section{India (in million)}

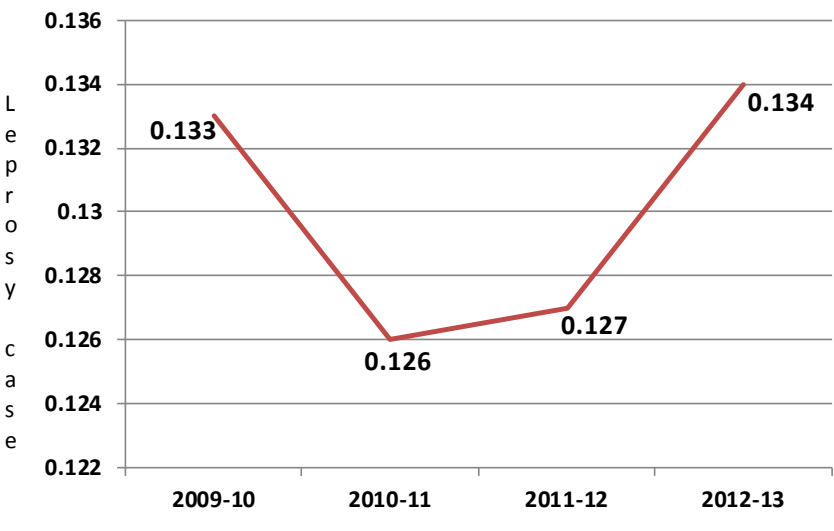

Figure 1: Trend of Leprosy cases in India.

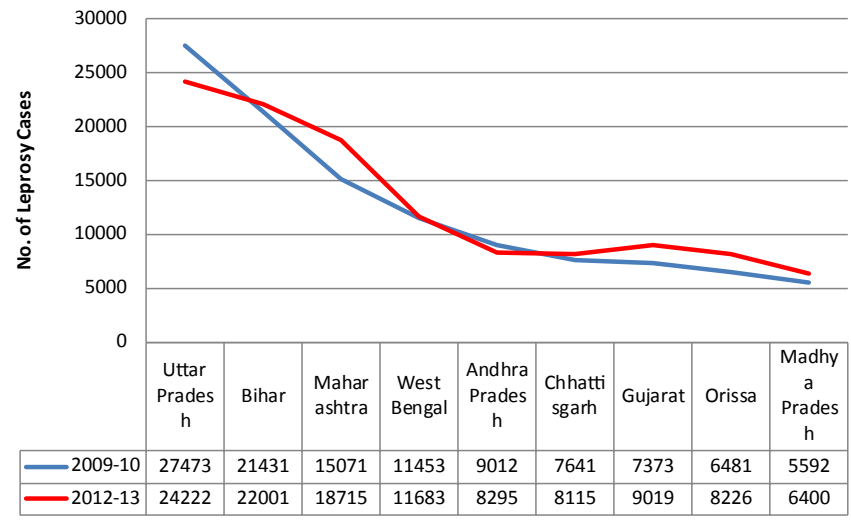

Figure 2: Trend of Leprosy cases in some states of India.

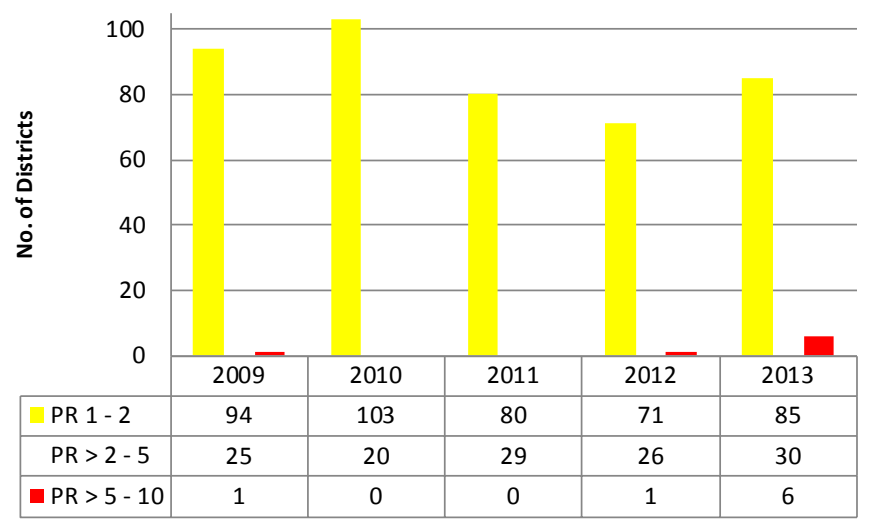

${ }^{*}$ PR- Prevalence rate

Figure 3: District wise trend of Prevalence rate of leprosy in India.

2012-13. Government statistics under estimate the extent of leprosy according to research organizations, NGOs and some medical personnel who argue that leprosy cases are on the rise [3]. The disease has returned in greater numbers in some of India's poorest states including Uttar Pradesh, Maharashtra and Bihar.

India has declared that it has leprosy under control, but the

*Corresponding author: Mane Abhay B, Department of Community Medicine, Smt. Kashibai Navale Medical College, Narhe, Pune, Maharashtra, India, Tel: 8975008663; E-mail: drabmane@yahoo.co.in

Received March 26, 2014; Accepted March 30, 2014; Published April 08, 2014

Citation: Mane Abhay B (2014) Leprosy on the Rise in India: Need to Adopt Enhanced Strategy for its Control. Primary Health Care 4: e111. doi:10.4172/21671079.1000e111

Copyright: (C) 2014 Mane Abhay B. This is an open-access article distributed under the terms of the Creative Commons Attribution License, which permits unrestricted use, distribution, and reproduction in any medium, provided the original author and source are credited. 


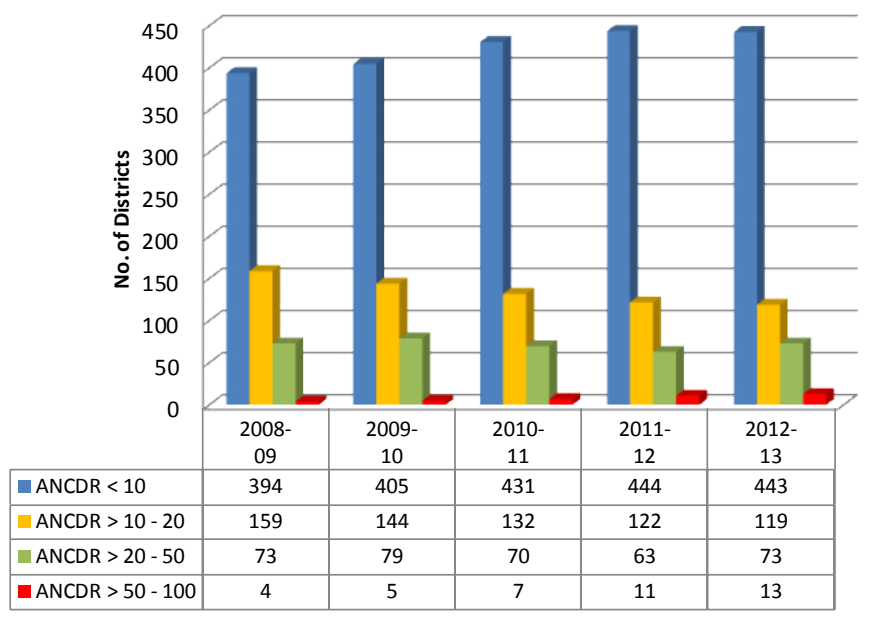

*ANCDR-Annual case detection rate

Figure 4: District wise trend of ANCDR of leprosy in India

numbers are showing a slow but clear rise in new cases. Officially, the National Leprosy Eradication Programme puts the current PR at 0.73 per 10,000 populations, higher than previous year which was 0.68 . A closer look at the data, however, shows that many states still have a very high prevalence of the disease, some even crossing the World Health Organization's standard for eliminating leprosy. Children, who are most susceptible to the mycobacterium, are indicators of whether a disease has spread in a neighborhood. In 9 states/ UTs more than $10 \%$ of new cases detected were children [4]. A high child proportion may be a sign of active and recent transmission of the disease. It is thus an important epidemiological indicator [5]. According to World Health Organization, new cases have increased in the past two years in India in tandem with an uptick in relapses in previously treated patients.

\section{Stigma Hinders the Efforts to Control Leprosy in India}

Ignorance has been blamed for delays in new sufferers seeking treatment. Because of the continuing stigma surrounding the disease many sufferers in India delay treatment [6]. While officials attribute the rise in numbers to a strong detection system, experts blame it on a flawed, target-driven execution of the national leprosy eradication programme. Relatives of people with leprosy are also negatively affected. Lack of knowledge about leprosy results in stigma and discrimination against both people who have or had leprosy as well as people they are related to or associate with. The stigma of leprosy endures in India, even though the country has made great strides against the disease, which is neither highly contagious nor fatal. Now the number of new annual cases has risen slightly after years of steady decline, and medical experts say the enormous fear surrounding leprosy is hindering efforts to finally eliminate it. The fear of leprosy is so great that people refuse to come forward for treatment. This has had an adverse effect on the success of the leprosy program. People continue to hide their leprosy from families and loved ones out of fear they will be ostracized. Employers regularly turn away people who have had the disease, even if they've been treated and cured. Many struggle to get driver's licenses and other routine documents. Even the disease-free children of leprosy patients are shunned.

The government is stepping up its fight against the disease, assigning additional health workers to 209 districts seen as high endemic areas in 16 states. The stigma and discrimination mitigation strategy like intermixing of patients and public along with awareness generation needs to be implemented at all levels. The rising figures indicate that transmission is far from being interrupted. The detection delay seems to increase in number of countries, with the danger that at term, slowly declining trends could be reversed. Effective multidrug therapy has resulted in a substantial decrease in the number of cases; there is still a need for better strategies for disease control and prevention of disability in affected individuals. Detection of all cases in a community and completion of treatment using MDT are the basic tenets of the enhanced global strategy [7]. The strategy also emphasizes the need to sustain expertise and increase the number of skilled leprosy staff, improve the participation of affected persons in leprosy services and mitigate the stigma associated with leprosy. The enhanced global strategy set as a target for 2015 the reduction of new cases with visible deformity or grade 2 disabilities (G2D) per 100000 people by $35 \%$ compared to the G2D rate of 2010 . There is a continuing need to improve data collection and monitoring of trends at local level as well as at country level. There is also a need to adopt local problem-specific strategies at state/district levels to address diverse factors influencing the leprosy situation in India. These complementary approaches are essential to achieve further reduction of the disease burden due to leprosy in accordance with the enhanced global strategy and as per the recommendations of WHO expert committee on leprosy [8].

\section{Acknowledgement}

The author is thankful to $\operatorname{Dr}$ (Air Cmdr) Kevin Fernandez, Professor \& Head Department of Community Medicine for his guidance and support. The author is also thankful to Dr A.V. Bhore, Dean, Smt. Kashibai Navale Medical College, Pune for his support.

\section{References}

1. WHO (2013) Weekly Epidemiological Record WHO, 88: 365-80.

2. GOI. NLEP -Progress Report for the year 2012-13. Central Leprosy Division. DGHS, GOI. New Delhi.

3. http://timesofindia.indiatimes.com/city/pune/Rise-in-leprosy-cases-in-Punedistrict/articleshow/24563919.cms

4. NLEP (2011) 'Progress Report for the year 2010-11 ending on 31st March 2011, Central Leprosy Division, Directorate General of Health Services, New Delhi.

5. GOI. Disability, MB and Child proportion-Epidemiological significance and interpretation. Central Leprosy Division, Directorate General of Health Services, New Delhi.

6. GOI. NLEP-guidelines on reduction of stigma and discrimination against persons Affected by leprosy. Central Leprosy Division, Directorate General of Health Services, New Delhi.

7. WHO. Enhanced global strategy for further reducing the disease burden due to leprosy.

8. WHO Expert Committee on leprosy .Geneva, World Health Organization, 2010, WHO Technical report series 968. 